\title{
Novas espacialidades urbanas: shopping centers - simulacro dos espaços públicos
}

\author{
Prof. Reginaldo Magalhães de Almeida \\ Centro Universitário de Belo Horizonte UNI-BH \\ Email: rmalmeida@acad.com.br
}

\begin{abstract}
Resumo: Este artigo tem como objetivo analisar uns dos fenômenos das cidades contemporâneas: os shopping centers. Tais equipamentos vêm simulando em seus espaços privatizados parte da urbanidade perdida nas cidades, ou seja, tornando-se os lugares do encontro, do diálogo, da liberdade, da socialização. Com o advento da cultura de massa e da sociedade de consumo, a recriação em ambientes fechados da ambiência existente nos espaços públicos é cada vez mais freqüente. Invadindo nossas cidades, o shopping center torna-se cada vez mais referência urbana. O texto é dividido em três seções, sendo a primeira dedicada à análise da cidade e às transformações do espaço público. A segunda avalia o equipamento shopping center. Na terceira parte, procura-se contextualizar os espaços recriados pelos shoppings e a cidade.
\end{abstract}

Palavras-chave: cidades, espaço público, shopping centers.

Abstract: This article's objective is to analyze a phenomenon of contemporary cities: the shopping malls. These structures try to replicate, in the privatized spaces they are in, part of the lost urbanity in cities. They have become places where people meet, have conversations, freedom, and where they socialize. With the arrival of mass culture in this consumer driven society, reestablishment of the public ambiance in open spaces in these closed spaces is becoming increasingly common. The malls, as they invade our cities, have turned into the reference for urban life. This article is divided into three parts: the first one analyzes the city and the transformation of public spaces. The second part analyzes the equipment of the malls. The third part tries to contextualize these recreated spaces in the malls and cities.

Word-key: cities, public spaces, shopping malls.

\section{INTRODUÇÃO}

As cidades passam por um grande problema: a perda dos espaços públicos está levando à sua recriação em ambientes fechados - os shopping centers.

Quando andamos pela cidade, somos afetados, de uma maneira ou de outra, pelos edifícios, por sua respectiva disposição no espaço, por sua relação com outros elementos e por sua aparência. Seja o que for que essa percepção espontânea indique ou projete, o espaço, de modo nenhum, é dado por si próprio, sendo fomentado por um conjunto significativo de objetos, tanto naturais, como construídos pelo homem. Na mente de todos, desde o criador até o utilizador ou o espectador, todo esse sistema - revestido da função arquitetônica, tratando-se de objeto concebido ou apropriado pelo homem estabelece uma moldura espacial própria e representativa dos desejos, sejam esses do tipo que forem: especulativos, opressores, democráticos, entre outros.

Praticamente todo esse cenário de espacializações, cenário arquitetônico, constitui um conjunto altamente complexo de sistemas espaciais, alguns subordinados, outros coordenados, uns tocando-se, outros atravessando ou outros ainda rodeando. No seu nível mais amplo, pode-se corresponder à configuração de toda uma cidade, subdividida em suas ruas, quarteirões, praças e também edifícios, onde a arquitetura expõe seus significados. Arnkeim considera que " $O$ 
simbolismo arquitetônico começa em ação quando o projeto de um edifício utiliza configurações que encerram um significado" [1].

Exaltando o simbolismo do espaço e a importância da arquitetura nesse processo, Mumford, historiador americano e crítico de arquitetura, conclui que ela possui um papel singular na transformação do ambiente, pois reflete e concentra uma variedade enorme de fatos sociais, entre os quais estão as crenças, os conhecimentos e os processos de organização de toda uma sociedade, revestindo de significação os impulsos e idéias que lhe deram forma e pondo a descoberto relações latentes ao exteriorizar as crenças, ou seja:

"No estado das construções de qualquer período, pode-se descobrir, em caracteres legíveis, os complexos processos e transformações que se verificaram dentro da própria civilização" [2].

O tempo atual constitui-se num mundo organizado em torno de simulacros $\mathrm{e}$ simulações, no qual os espaços da cidade são influenciados, transformando radicalmente as experiências do cotidiano de uma realidade perdida. O sociólogo e filósofo francês, Jean Baudrillard através de exemplos dos "novos centros de espetáculos, hipermercados, acidentes nucleares e novas tecnologias" [3], analisa a questão dos simulacros e da simulação, a geração, através de modelos sociais, de um real sem origem nem realidade.

Estes aspectos são marcadores fortes de diferenças entre a sociedade, cultura moderna e pós-moderna, na qual se torna impossível negar que existe uma dinâmica de consumo diferente, que entre outras coisas, pode ser representada no slogan de Baudrillard. A sociedade-cultura de consumo está associada à complexidade humana, ou seja, envolve seus valores, desejos, hábitos, gostos e necessidades, numa escala extremamente intensificada. $\mathrm{O}$ consumo transformou-se, segundo o autor, na moral do mundo contemporâneo e o espaço onde essas manifestações são mais visíveis é o shopping center.

Entretanto, a idéia que envolve os shopping centers não tem nada de novo, pois, desde os tempos antigos, esteve presente entre nós. No passado, à medida que se desenvolviam as cidades, as lojas iam-se aglutinando e acabavam por constituir o foco de toda a cidade e aldeia.

A alternativa de comprar era antigamente realizada nas ruas ou nos mercados. Esse desenvolvimento era feito sem planejamento e crescia desordenadamente. Alguns desses mercados existem como ruínas até hoje, como, por exemplo, o Mercado de Trajano (Século II d.C.), em Roma. Destinado à comercialização de redes e especiarias, peixes e frutas, aproximadamente 150 lojas comerciais, a maioria voltada para um grande corredor coberto, lembrando os shopping centers de hoje. Segundo Mumford " $O$ Mercado de Trajano, com sua concentração de lojas em três níveis, rivaliza com qualquer supermercado de hoje... sendo um milagre do planejamento compacto" [4].

O objetivo deste artigo é introduzir a análise das relações entre a cidade e os shoppings. Enquanto as cidades deparam-se cada vez mais com a decadência dos seus espaços públicos, como locais de sociabilização, e encontro, em contrapartida, existe uma proliferação de edifícios, os shoppings, que tentam simular parte dessa urbanidade perdida. O lema básico tem sido que nesses edifícios encontram-se segurança, beleza, tranquiilidade e alegria, qualidades cada vez mais raras nos espaços públicos.

Conhecer esse espaço privado é de fundamental importância para o levantamento dos elementos que possam possibilitar o resgate das qualidades que vêm perdendo os espaços públicos das cidades contemporâneas.

\section{A CIDADE}

A Revolução Industrial no século XIX, impôs novas formas de vida e de conhecimentos aos habitantes das cidades, que então se 
encontravam em rápido processo de expansão. Os drásticos efeitos - o choque entre as forças de produção que estavam emergindo e as crescentes aspirações de quem seria participante de seus benefícios ou mesmo daqueles excluídos desses benefícios apareceram de uma forma intensa no espaço das cidades.

Diversos pensadores, preocupados com a ordem do plano e com as fronteiras claras do espaço, respondiam ao aparente caos na base de formas ideais pré-elaboradas que, em princípio, eram legado da tradição renascentista. Os filósofos ou bem sonhavam com as utopias antiurbanas metafóricas, ou propunham esquemas práticos para a renovação e a extensão das cidades, que serviam para caracterizar, assimilar e organizar a percepção dessas novas realidades.

Alguns aspectos ou mesmo artifícios metafóricos eram responsáveis pelo tom dos planos e organizações, os quais, além de aparecerem na forma urbana, como também nos textos literários, atuavam ante os habitantes e a classe dominante da cidade como forma de representação desta. No Século XIX, essas metáforas eram extraídas das formas de produção científica e industrial. Nesse período, a natureza deveria ser domesticada, e os tumores da cidade tratados terapeuticamente.

$\mathrm{Na}$ cidade industrial, o desequilíbrio entre a oferta e a procura de alojamentos abre caminho à sobreposição dos interesses econômicos sobre o desenho urbano. No seu conjunto, a experimentação urbanística da segunda metade do Século XIX representaria a resposta às transformações sociais, econômicas e demográficas da Revolução Industrial. A ampliação da estrutura em grade urbana, com a intervenção direta da especulação (a qual assumiria o controle da cidade), e o sistema de transportes públicos foram as duas principais atividades que deram predominância às formas capitalistas na cidade crescente do Século XIX e configuraram tanto as áreas públicas como as ruas.
A relação do homem com o espaço arquitetônico é notória. Afirmar que as formas são expressivas significa dizer que manifestam objetivos mais elevados, eventualmente baseados em sistemas de valores.

As formas tornam-se expressivas, porque podem significar algo para nós. Pode-se falar também de formas simbólicas, expressão em que o símbolo significa algo completamente diferente de uma mera representação. Formas expressivas e formas simbólicas podem ser sinônimas, significando aquelas formas físicas (percebidas ou produzidas) que conduzem a uma alta significação. Norberg-Schulz, autor de diversos textos sobre arquitetura, conclui que "O simbolo-função é básico para todo comportamento humano. Sem símbolos que concretizem seus valores de orientação no mundo, o homem seria inexpressivo" [5].

Tanto o simbolismo no espaço físico como o espaço público sempre estiveram presentes na nossa cultura e foram importantes para o homem. É no espaço público que o homem experimenta, constrói e realiza os seus eventos. Norberg-Schulz afirma que:

"O interesse do homem pelo espaço tem raízes existenciais: deriva de uma necessidade de adquirir relações vitais no ambiente que o rodeia para aportar sentido $e$ ordem a acontecimentos $e$ ações" [6].

As atividades e necessidades humanas no espaço geram as espacializações, que são concretizadas pela arquitetura. Segundo diz a professora Maria Lúcia Malard, "As espacializações são a expressão, no espaço, das interações entre os eventos (formas sociais) e as coisas (formas físicas)" [7].

O homem tem inventado espaços, a fim de projetar a sua imagem do mundo por meio de suas criações. Isso ocorre em qualquer ambiente de que o homem se aproprie, o que vale dizer que qualquer ambiente é um "espaço expressivo", cujas propriedades podem ser conhecidas e sistematizadas. 
Dessa forma, o espaço arquitetônico assume um papel fundamental na materialização do espaço existencial do homem, pois representa o ambiente em que os eventos podem ocorrer.

Segundo lembra Norberg-Schulz "Os lugares são metas ou focos onde experimentamos os acontecimentos mais significativos de nossa existência, mas também são pontos de partida a partir dos quais nos orientamos e nos apoderamos do ambiente circundante" [8], sendo que, ao espacializar suas atividades, o homem cria os lugares.

Apesar de o automóvel já haver sido inventado, até 1920, quando se inicia sua produção em grande escala, ele não será instrumento fundamental, ao ponto de provocar mudanças na configuração das ruas. Um outro equipamento, o elevador, juntamente com o desenvolvimento tecnológico da construção metálica, no início do Século XX, tornou-se fundamental para empreender uma nova forma na configuração das ruas, da expansão horizontal das cidades para a expansão vertical. Ambos iriam mudar, de vez, o perfil do espaço urbano, em um ritmo inimaginável, permitindo cada vez mais edifícios altos, os quais se tornariam, anos mais tarde, símbolo do modernismo. Portanto, a congestão, anteriormente restrita ao espaço horizontal das ruas, iria invadir também o espaço vertical.

Os poderes públicos aderiram à urbanística moderna, oficializando-a e institucionalizando-a até a banalização. A estética, a arte urbana e o desenho vão tendo pouco valor em face dos graves e sérios problemas demográficos e sociais.

Assim, a urbanística, que nos últimos anos conduziu ao ordenamento territorial, destruiu a forma urbana. A cidade ficou sem espaços identificáveis e significantes, com tudo funcionalmente resolvido, mas de maneira insatisfatória.

Como alternativa ao modernismo, introduz-se na cidade um novo contexto dentro da teoria arquitetônica e urbanística, o pós-modernismo que, segundo afirma David Harvey, considera o tecido urbano “... como algo necessariamente fragmentado, um palimpsesto de formas superpostas umas às outras e uma colagem de usos correntes" [9], ou seja, a totalidade do espaço deixa de ser o princípio norteador, passando a assumir importância as partes que o compõem. A paisagem da rua adquire, dentro desse contexto, e de forma pontual, não só elementos coloridos e pluralismo estético, como também o high-tech e mesmo o deconstrutivismo. As opiniões contemporâneas tornam-se mais exigentes, já que passam a implicar que o efeito do entorno construído pode estender-se para alterar as formas de conduta e estimular os habitantes urbanos a adotarem novos modelos de ação social.

Embora havendo uma rica gama de movimentos, as propostas e intervenções, bem como simulações ainda não foram capazes de reverter as tendências de degradação das ruas da cidade contemporânea. Atualmente, as cidades procuram criar para os outros uma imagem positiva e "Para determinada imagem, a cidade através de organização de espaços urbanos espetaculares se tornou um meio de atrair capital e pessoas do tipo certo" [10].

O período entre o fim do Século XVIII e meados do Século XIX foi importante para o desenvolvimento dos shopping centers como os conhecemos hoje, junto com o aumento da produção industrial e as mudanças nas relações de compra e venda que então ocorreram no mercado, promovidas pela consolidação da Revolução Industrial. Essas relações estabeleceram espacializações que refletiram em novas estruturas arquitetônicas, as quais serão analisadas posteriormente.

Importante é que as cidades estão baseadas sobre dados políticos e abstratos não demonstráveis, e cuja aplicação, traduzida pela supressão da rua tradicional, bordejada de habitações, lojas, bares e restaurantes, produz nefastas consequiências para os habitantes. As ruas, revestidas dessas qualidades, seriam o lugar primordial para os contatos sociais quotidianos, o urbano como 
lugar do encontro, da simultaneidade, como o que foi, segundo sua compreensão, deixado de lado pelas novas urbanizações funcionalistas. A diversidade nas ruas não dá, em absoluto, uma impressão de "desorganização, fragmentação ou dispersão" [11]. Citando exemplos de ruas tradicionais de grandes cidades, conclui-se que os contatos nas ruas constituem a base dinâmica sobre a qual sustenta-se a vida pública sã de uma cidade, estando pautada na diversidade que esses espaços apresentam.

Pode-se afirmar que o Século passado e o atual vêm apresentando uma forte rejeição à vida pública. Com o advento da cultura de massa e da sociedade de consumo, uma nova urbanidade, decorrente da diversidade social e do anonimato do espaço urbano, esvaziou-se, em termos de trocas sociais simbólicas. Conforme lembra Arantes:

"A forma das grandes metrópoles onde as praças se transformam em simples pontos de passagem e as ruas, lugares suportes de fluxo de circulação para conjuntos verticais - constitui a ilustração mais eloqüente das relações entre o público e privado" [12].

No moderno, a rua não é a figura destacada de uma massa de sólidos, mas uma rua ilimitada de passagem.

Considerando o processo que vinha ocorrendo desde o século passado, para Baudrillard, o consumo transformou-se na moral do mundo contemporâneo e:

"Os novos mercados, artérias comerciais, superprisunic ${ }^{1}$, imitam uma natureza reencontrada e prodigiosamente fecunda, sendo os nossos vales de Canaã, onde correm, em vez do leite $e$ do mel, as ondas de néon sobre o ketchup e o plástico” [13].

${ }^{1}$ Superprisunic é o nome fantasia de uma rede de lojas francesa de preço único.
A supressão do espaço público vivo contém uma idéia ainda mais perversa: a de fazer o espaço contingente à custa do movimento. Tal como ocorre na maioria das áreas da cidade, o espaço público destina-se principalmente à passagem, não à permanência, e, como afirma o professor Sennett:

"A idéia do espaço público como derivação do movimento corresponde exatamente às relações entre espaço e movimento produzidos pelo automóvel particular... As ruas da cidade adquirem então uma função peculiar: permitir a movimentação; se elas constrangem demais a movimentação, por meio de semáforos, contramãos, etc., os motoristas se zangam ou ficam nervosos" [14].

\section{O EDIFÍCIO}

Nos Estados Unidos, no início do Século XX, surgiram novos tipos de centros comerciais. Os embriões dos atuais shopping centers começaram com o benefício de disponibilidade de terra, como um projeto concebido nos E.U.A. Contaram também com a contribuição da emergência do consumo de massa, a política estatal de apoio à construção civil, a difusão do uso do automóvel, a abertura de estradas de boa qualidade, a concentração de capital e o marketing.

O automóvel junto com a geladeira estabeleceram novos hábitos para a população americana, a partir do início do Século XX. Com o automóvel, era possível percorrer maiores distâncias, e a geladeira permitia a estocagem de alimentos, possibilitando fazer compras com menos freqüência. Segundo afirmam autores como o arquiteto Rybczynski, junto aos dois equipamentos anteriormente citados, também "o supermercado mudou os hábitos da compra" [15]. Mas, como eram necessárias para a instalação dos supermercados, áreas cada vez maiores, com os conseqüentes pátios de estacionamento, foram-se implantando nas regiões periféricas das cidades americanas, o que já não acontecia com as lojas de 
departamentos, que continuavam a funcionar no centro das cidades.

Segundo informa o Urban Land Institute [16], instituição privada de pesquisas de uso do solo, em 1907, surgiu o primeiro embrião dos modernos shoppings centers, caracterizado pela arquitetura uniforme das lojas e por uma área específica para estacionamento, em Roland Park, próxima a Baltimore, E.U.A. Seguindo o estilo dos "shoppings village", possuía lojas construídas e alugadas por um só investidor, muitas vezes com estacionamento grátis, tudo próximo a um subúrbio planejado.

A partir da década de 50, surge uma nova tipologia de shopping centers. Com o projeto do arquiteto Victor Gruen, em 1956, foi inaugurado em um subúrbio de Minesota, o Southadale, um centro comercial que apresentava áreas de circulação interna fechadas, com ar condicionado e aquecimento, inspirado, segundo o arquiteto, nas galerias de teto de vidro de Milão e Nápoles do Século XIX. Pode-se considerar essas áreas da circulação como os primeiros malls. O sucesso de tal empreendimento, que possuía mais de um andar, surpreendeu a todos. Rybczynski afirma que a partir da década de 60, “... a maioria dos novos shoppings regionais, com o sucesso de Southadale, eram fechados" [17].

No Brasil, todos os estudos que analisam os shopping centers são unânimes em afirmar que a década de 80 marca o início da eclosão desses edifícios, embora o Shopping Iguatemi tenha sido inaugurado em São Paulo, no ano de 1966. No início, demorou um pouco para os comerciantes acreditarem no sucesso do empreendimento, pois os lojistas achavam absurdo abrir as lojas para um local fechado e não para a rua, considerando, além disso, que o consumidor continuava preferindo fazer suas compras e seu footing em ruas da região central, como a Augusta ou a Barão de Itapetininga.

Até agosto de 1998, existiam, no Brasil, 150 unidades de shopping centers, sendo $143 \mathrm{em}$ operação e sete em construção. Destes, o tipo Regional responde por $78 \%$ do total. Os restantes são shoppings centers comunitários, de vizinhança, especializados, outlet center e festival center - dados da ABRASCE (Associação Brasileira de Shopping centers). [18]. Hoje, esse número quadruplicou. O shopping center regional é responsável pela comercialização de mercadorias em geral e serviços variados, distribuídos em lojas de departamentos ou hipermercados, sendo geralmente fechados em torno de uma circulação ou mall, como é o caso do $\mathrm{BH}$ Shopping situado na capital mineira.

Para autores como Pintaudi, os shopping centers eclodem com o desenvolvimento, na economia brasileira, dos monopólios comerciais, favorecidos pelo crescimento das atividades varejistas, que antes não concentravam poder econômico, exceto poucas redes de supermercados ou grandes lojas. Essas transformações comerciais foram possíveis devido "à produção em massa, à concentração crescente de pessoas nas cidades, ao aumento qualitativo do consumo e à generalização do uso do automóvel" [19].

Conforme dados censitários de 1940, a população urbana do Sudeste do Brasil atingia $39 \%$ da região. Em 1960, esse índice chegou a $57 \%$, e, em 1980 , a quase $83 \%$, ou seja, a maioria da população vivia nas cidades, sendo boa parte nas capitais da região sudeste [20]. Logo, na década de 80 , era grande o contingente populacional e, conseqüentemente, consumidor existente nas grandes cidades brasileiras.

Segundo Pintaudi afirma, outro fator favoreceu o surgimento e desenvolvimento dos shopping centers no Brasil, a partir de meados da década de 60: os recursos oriundos do "setor privado" e do "setor público" [21], tais como os financiamentos de bancos estatais, como a Caixa Econômica Federal .

Atualmente, os shoppings centers continuam a evoluir, à medida que o mercado e as aspirações populacionais se modificam. Para diversos autores, a idéia do shopping center como um edifício contendo grande número de vagas para estacionamento e lojas comerciais, com o decorrer dos anos, além de sofrer 
alterações, vem segundo a arquiteta Bruna incorporando novos padrões, como, por exemplo, oferecer:

“... respostas espaciais para vários conflitos, como o de pedestres $e$ veículos, circulação de carga $e$ estacionamento, oferecer recreação $e$ lazer, além de comércio; possibilitar segurança e conforto aos clientes; fornecer serviços especializados, entre outros" [22].

Além disso, sua própria estrutura organizacional de simples shopping center local ao longo de uma área residencial e em torno de uma única loja âncora, evoluiu para a sofisticação dos regionais.

\section{CONSIDERAÇÕES FINAIS}

Este artigo chamou a atenção para o fato das simulações, transformações e características atuais do espaço público nas cidades contemporâneas.

Embora havendo uma rica gama de movimentos, conforme se viu anteriormente, as propostas, intervenções, bem como simulações ainda não foram capazes de reverter às tendências de degradação das ruas da cidade contemporânea. Atualmente, as cidades procuram criar para os outros uma imagem positiva e têm procurado uma arquitetura e formas de projeto urbano que atendam a essa necessidade. Harvey confirma tal hipótese ao afirmar que "Para determinada imagem, a cidade através de organização de espaços urbanos espetaculares se tornou um meio de atrair capital e pessoas ...” [23].

Hoje, percebe-se a simulação do espaço da cidade presente nos interiores de grandes edifícios como os shopping centers, que procuram recriar atmosferas desejadas na urbanidade perdida, tendo em vista os problemas por que passam as grandes cidades, tais como criminalidade, engarrafamentos, poluição etc.
Para aumentar a atração de pessoas e consumidores, as atividades dentro dos shopping centers não se vêm restringindo apenas à compra. Teatros são abertos, como também vários outros tipos de serviços, como lavanderias, chaveiros, dentre outros. Observa-se, nos novos projetos desses equipamentos, que se dá cada vez mais, atenção às ambientações em torno do lazer, junto com as áreas de alimentação, onde se agrupam bares, lanchonetes e restaurantes, os quais vêm proporcionando a atração de um grande fluxo de pessoas.

Só que todos os problemas urbanos e os artifícios projetuais dos shopping centers, ainda não conseguiram retirar todo o glamour do espaço das cidades e importância para as relações humanas. Ainda vemos pessoas sentadas nos bancos das praças, assistindo ao movimento de ir e vir; ainda pode-se caminhar pelas calçadas de nossas cidades; palavrear com um amigo; fazer passeatas, expondo os sentimentos e pensamentos.

O espaço urbano é complexo e nele coexistem diversos atores. Compreender esse espaço é fundamental, para que possamos identificar suas qualidades físico-espaciais, verificar as necessidades comportamentais das pessoas, levantando um arcabouço para a resolução de seus problemas.

Sem levar em conta a falta de segurança, que é resultante de questões socioeconômicas, desejamos de nossas ruas: prédios bonitos, passeios onde seja possível caminhar com conforto, largos ajardinados, bancos para sentar, ver e ser vistos.

A cidade, mesmo com todos os conflitos mantém o seu glamour. Ainda é um lugar de relevância e, sem dúvida, pode-se contribuir para sua revitalização, não só como tarefa de maquiagem urbana, considerando apenas a imagem, mas proporcionando mais conforto às pessoas, atendendo aos seus desejos e necessidades, não só vinculados ao desenvolvimento de atividades voltadas para o comércio, como também para o encontro. A sua simulação em espaços fechados como os 
shopping centers é uma realidade, porém ainda não a substitui.

\section{REFERÊNCIAS BIBLIOGRÁFICAS}

[1] ARNKEIM, Rudolff. A dinâmica da forma arquitetônica. Lisboa: Presença, p.170, 1988.

[2] MUMFORD, Lewis. A cultura das cidades. Belo Horizonte: Editora Itatiaia, p.417, 1961.

[3] BAUDRILLARD, Jean. Simulacros e Simulações. Lisboa: Edições 70, 2007.

[4] MUMFORD, Lewis. A cidade na história, suas origens transformações $e$ perspectivas. São

Paulo: Ed. Martins Fontes, p.15, 1982.

[5] NORBERG-SCHULZ, Christian. Existência, espacio e arquitectura. Barcelona: GG, p.46, 1975.

[6] Id., ibid., p. 9, 1975.

[7] MALARD, Maria Lúcia. O mito das aparências. Belo Horizonte: UFMG, p. 28, 1997.

[8] NORBERG-SCHULZ, Christian. $O p$. Cit., p.22, 1975.

[9] HARVEY, David. Condição pósmoderna. São Paulo: Edições Loyola, p.200, 1996.

[10]Id., ibid., p. 91, 1996.

[11]JACOBS, Jane. Muerte y vidas de Ias grandes ciudades norte-americanas. Madrid: Ed. Península, p.243, 1973.

[12] ARANTES, Otília Beatriz Fiori. O lugar da arquitetura depois dos modernos. São Paulo: Editora Universidade de São Paulo, p. 13, 1995.

[13] BAUDRILLARD, Jean. Op. Cit., p.13, 2007.
[14]SENNETT, Richard. O declínio do homem público. São Paulo: Companhia das Letras, p. 28, 1988.

[15]RYBCZYNSKI, Witolet. Vida nas cidades: expectativas urbanas. Rio de Janeiro: Record, p. 183, 1996.

[16] URBAN LAND. Winning shopping center design.. New York : Retail Reporting Corporation, 1998.

[17]RYBCZYNSKI, Witolet. Op. Cit., p. 188, 1996.

[18]ABRASCE. Associação Brasileira de Shoppings Centers, 1998.

[19] PINTAUDI, Silvania Maria, FRÚGOLI Jr., Heitor (Org.). Shopping centers: espaço, cultura e modernidade nas cidades brasileiras. São Paulo: UNESP, p. 26, 1992.

[20]ANUÁRIO ESTATÍSTICO DO BRASIL. Rio de Janeiro: IBGE, 2001.

[21]PINTAUDI, Silvania Maria, FRÚGOLI Jr., Heitor (Org.). Op. Cit, p.27, 1992.

[22]BRUNA, Gilda Collet. As últimas tendências em shoppin centers. Projeto/design, São Paulo, $\mathrm{n}^{\circ} 119$, agosto, $\mathrm{p}$. 95, 1995.

[23] HARVEY, David. Op. Cit., p.91, 1996. 